\title{
FDA National Drug Code
}

National Cancer Institute

\section{Source}

National Cancer Institute. FDA National Drug Code. NCI Thesaurus. Code C54185.

A unique numeric code assigned by the U.S. Food and Drug Administration to prescription drugs and insulin products manufactured, prepared, processed, or propagated by registered establishments for commercial distribution. U.S. prescription drugs must use an NDC; most non-prescription drugs are also primarily referenced by NDC. NDC codes change often as companies merge, new products are introduced, and drugs are retired. Each code is a unique 10-digit, 3-segment number in one of the following configurations: $4-4-2,5-3-2$, or 5-4-1. The first, labeler code segment is assigned by the FDA to identify the establishment. The second, product code segment identifies a specific strength, dosage form, and formulation for a particular firm. The third, package code segment identifies package sizes and types. Both the product and package codes are assigned by the establishment. An asterisk may appear as a placeholder in the second or third segments. 